\title{
Administration of Thyrotropin-Releasing Hormone in the Hypothalamic Paraventricular Nucleus of Male Rats Mimics the Metabolic Cold Defense Response
}

\author{
Zhi Zhang a, e Frederico Machado ${ }^{\text {b, e }}$ Li Zhao ${ }^{\text {e }}$ Charlotte A. Heinen ${ }^{a}$ \\ Ewout Foppen $^{\text {a }}$ Mariette T. Ackermans ${ }^{c}$ Jiangning Zhou ${ }^{d}$ Peter H. Bisschop ${ }^{a}$ \\ Anita Boelen $^{\mathrm{a}}$ Eric Fliers ${ }^{\mathrm{a}}$ Andries Kalsbeek ${ }^{\mathrm{a}, \mathrm{e}}$ \\ a Department of Endocrinology and Metabolism, Amsterdam UMC, University of Amsterdam, Amsterdam, The \\ Netherlands; ${ }^{b}$ Department of Physiology and Biophysics, Institute of Biological Sciences, Federal University of \\ Minas Gerais, Belo Horizonte, Brazil; ' Laboratory of Endocrinology, Department of Clinical Chemistry, Amsterdam \\ UMC, University of Amsterdam, Amsterdam, The Netherlands; ${ }^{d}$ CAS Key Laboratory of Brain Function and Disease,

 \\ Mechanisms, Netherlands Institute for Neuroscience (NIN), Amsterdam, The Netherlands
}

\section{Keywords}

Thyrotropin-releasing hormone $\cdot$ Cold $\cdot$ Hypothalamus · Autonomic nervous system · Liver · Brown adipose tissue · Glucose

\footnotetext{
Abstract

Background: Cold exposure increases thyrotropin-releasing hormone (TRH) expression primarily in the hypothalamic paraventricular nucleus (PVN). The PVN is a well-known hypothalamic hub in the control of energy metabolism. TRH terminals and receptors are found on PVN neurons. We hypothesized that $\mathrm{TRH}$ release in the PVN plays an important role in the control of thermogenesis and energy mobilization during cold exposure. Methods: Male Wistar rats were exposed to a cold environment $\left(4^{\circ} \mathrm{C}\right)$ or TRH retrodialysis in the PVN for $2 \mathrm{~h}$. We compared the effects of cold exposure and TRH administration in the PVN on plasma glucose, corticosterone, and thyroid hormone concentrations, body temperature, locomotor activity, as well as metabolic gene ex-
}

pression in the liver and brown adipose tissue. Results: Cold exposure increased body temperature, locomotor activity, and plasma corticosterone concentrations, but blood glucose concentrations were similar to that of room temperature control animals. TRH administration in the PVN also promptly increased body temperature, locomotor activity and plasma corticosterone concentrations. However, TRH administration in the PVN markedly increased blood glucose concentrations and endogenous glucose production (EGP) compared to saline controls. Selective hepatic sympathetic or parasympathetic denervation reduced the TRH-induced increase in glucose concentrations and EGP. Gene expression data indicated increased gluconeogenesis in liver and lipolysis in brown adipose tissue, both after cold exposure and TRH administration. Conclusions: We conclude that TRH administration in the rat PVN largely mimics the metabolic and behavioral changes induced by cold exposure indicating a potential link between TRH release in the PVN and cold defense.

(c) 2018 The Author(s)

Published by S. Karger AG, Basel

\begin{tabular}{ll}
\hline KARGER & $\begin{array}{l}\text { ( } 2018 \text { The Author(s) } \\
\text { Published by S. Karger AG, Basel }\end{array}$ \\
E-Mail karger@karger.com & $\begin{array}{l}\text { This article is licensed under the Creative Commons Attribution- } \\
\text { NonCommercial-NoDerivatives 4.0 International License (CC BY- } \\
\text { NC-ND) (http://www.karger.com/Services/OpenAccessLicense). } \\
\text { Usage and distribution for commercial purposes as well as any dis- } \\
\text { tribution of modified material requires written permission. }\end{array}$
\end{tabular}

Andries Kalsbeek, $\mathrm{PhD}$

Department of Endocrinology and Metabolism

G2-133, Amsterdam UMC

Meibergdreef 9, NL-1105AZ Amsterdam (The Netherlands)

E-Mail a.kalsbeek@ amc.uva.nl 


\section{Introduction}

An efficient cold defense mechanism requires an accurate coordination of energy sources (e.g., glucose and fatty acids) and heat production (e.g., shivering and adaptive thermogenesis). The central thyrotropin-releasing hormone (TRH) system is known to be involved in thermoregulation and glucose metabolism, two important adaptive systems during cold exposure, through both endocrine and neuronal pathways $[1,2]$. Indeed, TRH administration, either peripherally or centrally, has strong effects on glucose metabolism [3] and body temperature regulation [4-6]. In addition, animals with TRH deficiency exhibit impaired cold tolerance $[7,8]$ and glucose metabolism [9].

The hypothalamic paraventricular nucleus (PVN) is an important integration center for the neuroendocrine and autonomic regulation of energy metabolism [10-12]. Both anatomical and functional evidence have suggested PVN as a pivot for autonomic regulation of glucose metabolism and brown adipose tissue (BAT) thermoregulation [13-15]. Even though earlier studies have suggested a central role of TRH in energy metabolism $[4,5,16]$, the function of TRH in the PVN in energy homeostasis has never been investigated. TRH receptors are present in the PVN $[17,18]$, and TRH-immunoreactive axon terminals make synaptic contact with both TRH and non-TRH neurons in the PVN $[19,20]$. Notably, within the hypothalamus, early cold exposure increases TRH mRNA and peptide expression exclusively in the PVN $[21,22]$, pointing to a key role for TRH in the PVN during cold exposure. In view of these lines of evidence, we hypothesized that TRH release in the PVN plays a critical role in the control of two essential responses during cold adaptation, i.e. glucose metabolism and thermoregulation. Therefore, in the present study, we compared the effects of cold exposure and TRH administration locally in the PVN on circulating thyroid hormone, glucose, and corticosterone concentrations, body temperature, locomotor activity, as well as relevant gene expression in the liver and BAT. Our data indicate a central role for TRH in the PVN in regulating glucose metabolism and thermogenesis during a cold challenge.

\section{Methods}

\section{Animals}

Male Wistar rats weighing 300-350 g (Harlan Nederland, Horst, Netherlands) were housed individually in a $12 \mathrm{~h} / 12 \mathrm{~h}$ light/ dark cycle environment (lights on at 07:00), at a room temperature of $23 \pm 2{ }^{\circ} \mathrm{C}$ and $60 \pm 5 \%$ humidity. Chow and water were provided ad libitum unless stated otherwise. All animal experiments were carried out in accordance with the guidelines in The Netherlands and were approved by Animal Care Committee of the Royal Netherlands Academy of Arts and Sciences (KNAW).

\section{Surgery}

After 1 week acclimatization in the facility, animals were anesthetized by an intramuscular injection of a mixture of ketamine $(80$ $\mathrm{mg} / \mathrm{mL})$, xylazine $(8 \mathrm{mg} / \mathrm{mL})$, and atropine $(0.1 \mathrm{mg} / \mathrm{mL})(4: 2: 1$, $\mathrm{v}: \mathrm{v}: \mathrm{v})$ at a dosage of $1 \mathrm{~mL} / \mathrm{kg}$ body weight. Animals were allowed to recover from the surgery for at least 1 week and until their body weight had reached pre-surgery levels.

\section{Experimental Groups}

\section{Experiment 1}

Eighteen animals were divided into three experimental groups. Animals in group $1(n=6)$ received nano-thermo loggers (StarOddi Ltd., Iceland) both subcutaneously $\left(\mathrm{T}_{\mathrm{sc}}\right)$ just above the interscapular BAT and intraperitoneally attached to the abdominal muscle layer $\left(\mathrm{T}_{\mathrm{ip}}\right)$ for continuous body temperature recording. During the experiment, rats were housed in calorimetric cages within an air-conditioned chamber (TSE Systems GmbH, Bad Homburg, Germany) at either room temperature $\left(23^{\circ} \mathrm{C}\right)$ for 3 days with a cold challenge $\left(4^{\circ} \mathrm{C}\right)$ for $2 \mathrm{~h}$ at day 2 , or at room temperature for 3 days continuously. Metabolic parameters, i.e. $\mathrm{O}_{2}$ consumption, respiratory exchange rate, and locomotor activity were monitored. Animals were studied in a crossover design in both conditions with a 1-week interval (i.e., each animal served as its own control). Experimental groups $2(n=5)$ and $3(n=7)$ received an intraatrial silicone cannula implanted through the right jugular vein for blood sampling. During the experiment, rats were exposed to either room temperature $\left(23^{\circ} \mathrm{C}\right.$; group 2$)$ or cold temperature $\left(4^{\circ} \mathrm{C}\right.$; group 3$)$ for $2 \mathrm{~h}$ in a modified refrigerator where blood sampling was possible, without touching the animals, through the jugular vein cannula and a hole in the door.

\section{Experiment 2}

Fifty-eight animals received bilateral microdialysis (MD) probes adjacent to the PVN, for retrodialysis, using a stereotaxic apparatus (coordinates from Bregma: anteroposterior: $-1.8 \mathrm{~mm}$, lateral: $+2.0 \mathrm{~mm}$, depth: $-7.9 \mathrm{~mm}$, angle of arm: $\left.8^{\circ}\right)[23,24]$. The $\mathrm{U}$-shape tip of the MD probe was $1 \mathrm{~mm}$ long, $0.5 \mathrm{~mm}$ wide and 0.2 $\mathrm{mm}$ thick. Probe placements were checked in $20 \mu \mathrm{m}$ cresyl violetstained brain sections of each animal at the end of the experiment. Probe locations were scored from 0 to 4 on each side $(0$ being not in the hypothalamus, 1 being too far away from the PVN, 2 being close but too dorsal, 3 being almost correct but a little off, and 4 being a perfect placement) blindly with 2 people. Then, we added up the scores from both sides. Only animals with a total score higher than 4 were included in the final analysis, meaning that at least at one side the probe was very close to the PVN (see online suppl. Fig. S3; see www.karger.com/doi/10.1159/000492785 for all online suppl. material). Animals in experiment $2 \mathrm{~A}$ (TRH MD, $n=18$ ) also received a jugular vein cannula for stable glucose isotope infusion and a carotid artery cannula for blood sampling. In experiment $2 \mathrm{~B}$ (TRH MD, $n=20$ ), in addition hepatic sympathectomy (HSX), hepatic parasympathectomy (HPX) or sham surgery was performed as reported previously [25]. Briefly, sympathetic or para- 
sympathetic nerve bundles were cut using microsurgical instruments. Any connective tissue attachments between the hepatic artery and portal vein were also dissected, eliminating any possible nerve crossings. Animals with sham denervation surgery received the same manipulation as described above except for cutting the nerve. During TRH MD experiments, animals were connected to a metal collar hanging by a counterbalanced arm on the day before the actual experiment, i.e. the 2 -h TRH administration. Food was restricted to $20 \mathrm{~g}$ overnight, which is only slightly less than the average consumption per night (i.e., $24 \pm 2 \mathrm{~g}$ ) for rats with a similar body weight. Two hours before the experiment, rats were connected to tubing for blood sampling, tracer infusion, and TRH administration. In experiments $2 \mathrm{~A}$ and $2 \mathrm{~B}$, three blood samples were taken at $-25,-20$, and 0 min for basal glucose and corticosterone measurement. At time 0 (between 12:00 and 13:45), TRH (40 mM, Sigma-Aldrich, Germany) or Ringer's solution was perfused via the MD probes into the PVN at a speed of $3 \mu \mathrm{L} / \mathrm{h}$ for $2 \mathrm{~h}$. The dose and route of TRH perfusion chosen in the present study will result in an estimated dose of $0.2 \mu \mathrm{g} / \mathrm{h}$, which is within the lower range of other TRH studies in rat (0.1-40 $\mu$ g single injection) $[4,16,26-$ 28 ], but comparable to the TRH concentration during cold exposure (35-45 pg/15 $\mathrm{min}$ ) as measured by push-pull perfusion [22]. Blood samples of $100 \mu \mathrm{L}$ were withdrawn every $20 \mathrm{~min}$, and blood glucose concentrations were determined. To assess endogenous glucose production (EGP), $\left[6,6-{ }^{2} \mathrm{H}_{2}\right]$ glucose (D2 glucose) was used as a tracer. Blood samples were taken at -125 min for background enrichment, and at $-30,-25$ and -20 min to determine enrichment during the equilibrium state and every $20 \mathrm{~min}$ from time 0 to $120 \mathrm{~min}$ to determine enrichment during the experiment. In experiment $2 \mathrm{C}$ (TRH MD, $n=20$ ), animals were only provided with subcutaneous nanothermo loggers and MD probes as described above. TRH or Ringer's solution was perfused via MD probes into the PVN for $2 \mathrm{~h}$. Locomotor activity was monitored using an analog piezo-electric stabilimeter with a sample rate of once every $6 \mathrm{~min}$ as described before [29]. The rat cages were placed on a baseplate, where the voltage output of the sensors is proportional to relative changes in pressure, i.e. activity of the rat. No blood samples were taken, and the animals were decapitated immediately after the $2 \mathrm{~h}$ of TRH or Ringer's solution administration.

\section{Blood and Plasma Analysis}

Blood glucose concentration was determined by a glucose meter (Freestyle ${ }^{\mathrm{TM}}$, Abbott, the Netherlands) during the experiment. Plasma $\left[6,6-{ }^{2} \mathrm{H}_{2}\right]$ glucose enrichment was measured by gas chromatography-mass spectrometry as described previously [30]. EGP was calculated by the method of Steele [31]. Plasma corticosterone concentration was measured with radio-immunoassay kits (MP Biomedicals, Orangeburg, NY, USA). Plasma triiodothyronine (T3) and thyroxine (T4) concentrations were determined using an in-house radioimmunoassay as reported before (interassay variation $\mathrm{T} 3,6.2 \%$, and $\mathrm{T} 4,7.3 \%$; intraassay variability $\mathrm{T} 3,3.6 \%$, and T4, 6.6\%) [32]. Plasma thyroid-stimulating hormone (TSH) was determined by a chemiluminescent immunoassay, using the Immulite 2000 and a rat-specific standard (Siemens, Munich, Germany) with an interassay variation of $\pm 9 \%$ and an intraassay variation of $3-4 \%$. Within the same experiment, all samples were measured in one run to prevent interassay variation.

TRH in the PVN and the Cold Defense Response
RNA Isolation and Quantitative PCR

Total RNA from BAT and liver was isolated using MacheryNagel RNA isolation kit (Macherey-Nagel GmbH \& Co. KG, Düren, Germany), and RNA yield was determined using the DeNovix DS-11 Spectrophotometer (DeNovix, Wilmington, DE, USA). cDNA synthesis was performed with equal RNA input using the Transcriptor First Strand cDNA synthesis kit (Roche Molecular Biochemicals, Mannheim, Germany). As a control for genomic DNA contamination, we included a cDNA synthesis reaction without reverse transcriptase. Quantitative PCR was performed using the LightCycler 480 (Roche Molecular Biochemicals) and SensiFAST ${ }^{\text {TM }}$ SYBR No-ROX mix (Bioline, GmbH, Germany). The primers used for quantitative PCR are listed in online supplementary Table S1. Quantification was performed using the LinReg software (http://LinRegPCR.nl); PCR amplification efficiencies out of $5 \%$ of the mean were excluded from analysis [33]. Values were expressed relative to the geometric mean of the two reference genes: Gapdh and Hprt which showed stable expression across treatments (online suppl. Fig. S4).

\section{Statistical Analysis}

Data are expressed as mean \pm standard error of the mean. All analyses were performed with GraphPad Prism 6.05. Differences between two groups were analyzed using an independent twotailed Student's $t$ test. The difference between rats exposed to TRH or cold and their respective control groups during the time-series blood sampling experiments was evaluated by two-way ANOVA with repeated measurements followed by Sidak post hoc analysis. Significance was defined at $p<0.05$.

\section{Results}

\section{Cold Exposure Increases Plasma Thyroid Hormones,}

TSH, and Corticosterone Concentrations

Plasma T3 and T4 concentrations were significantly increased $30 \mathrm{~min}$ after cold exposure (Time, $p=0.008$; Treatment, $p=0.006$; Time $\times$ Treatment, $p=0.003$; and Time, $p=0.025$; Treatment, $p=0.037$; Time $\times$ Treatment, $p=0.014$ ) (Fig. 1a, b). The increases in T3 and T4 continued until the end of the experiment. Plasma TSH was also markedly increased during cold exposure with a peak value about $60 \mathrm{~min}$ after the start of the cold exposure (Time, $p=0.004$; Treatment, $p=0.003$; Time $\times$ Treatment, $p<$ 0.001 ) (Fig. 1c), as were plasma corticosterone concentrations (Time, $p<0.001$; Treatment, $p=0.015$; Time $\times$ Treatment, $p=0.028$ ) (Fig. 1d).

\section{Cold Exposure Increases Body Temperature, Energy Expenditure, and Locomotor Activity but Does Not Affect Blood Glucose}

When exposed to a cold environment, both subcutaneous $\left(\mathrm{T}_{\mathrm{sc}}\right)$ and core $\left(\mathrm{T}_{\mathrm{ip}}\right)$ body temperature were increased within the first hour $\left(\mathrm{T}_{\mathrm{sc}}\right.$ : Time, $p=0.002$; Treat- 


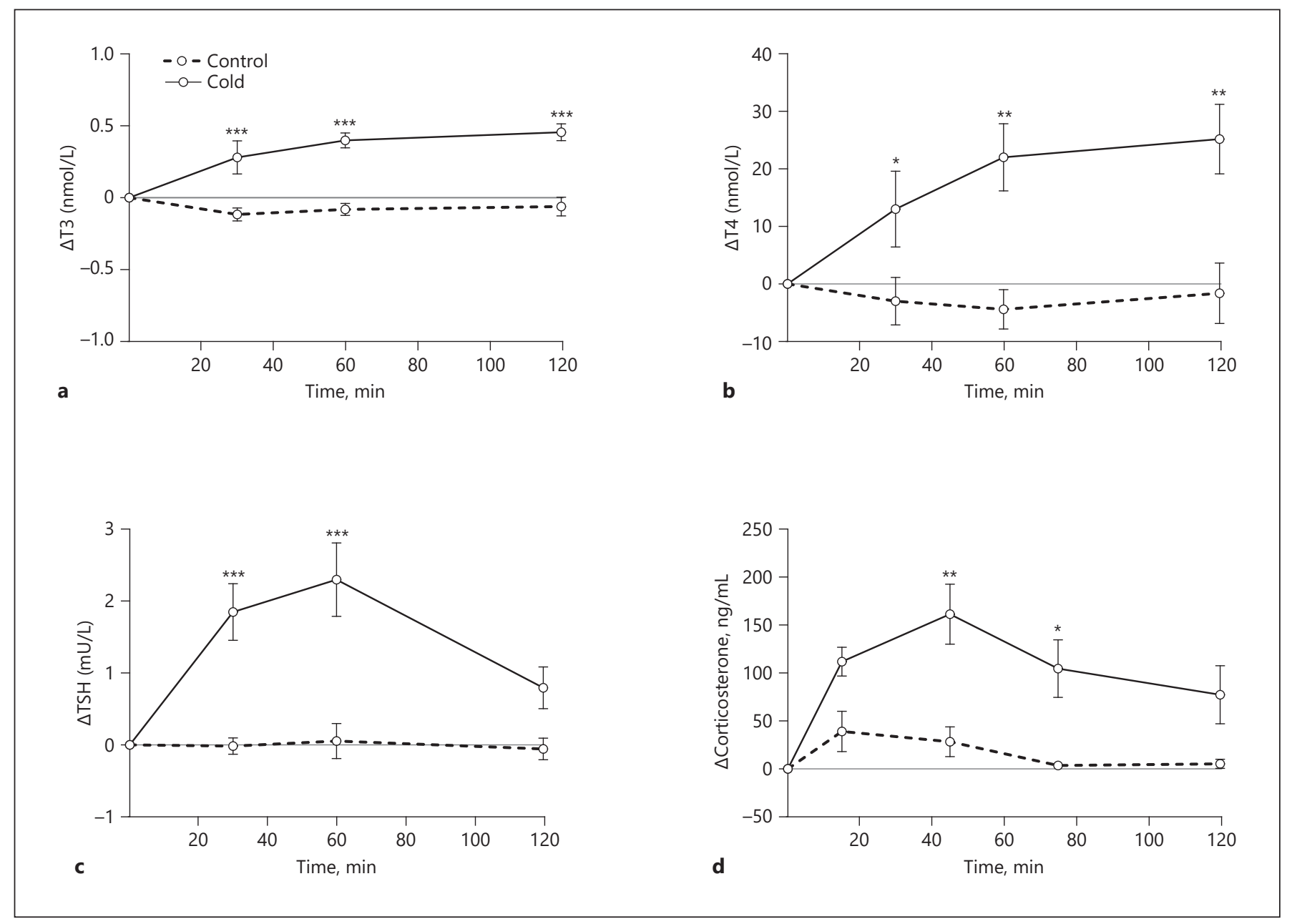

Fig. 1. Effects of cold exposure on plasma thyroid hormones and corticosterone concentrations. T3 (a), T4 (b), TSH (c), and corticosterone (d) concentrations were determined at 0, 30, 60, and 120 min after starting the cold exposure. Data are shown as the absolute increase (delta) compared to the basal samples before treatments. Basal values are shown in online supplementary Table S2. $n=5-7$ per group. Asterisks indicate significant differences between groups at individual time points. Post hoc between cold and control groups, ${ }^{*} p<0.05,{ }^{* *} p<0.01,{ }^{* * *} p<0.001$.

ment, $p=0.021 ;$ Time $\times$ Treatment, $p=0.121 ; \mathrm{T}_{\mathrm{ip}}$ : Time, $p=0.074$; Treatment, $p=0.021$; Time $\times$ Treatment, $p=$ 0.010 ) (Fig. 2a, b). $\mathrm{T}_{\text {ip }}$ was increased earlier (i.e., $20 \mathrm{~min}$ after the onset of cold exposure) and for a longer period (up to $80 \mathrm{~min}$ ) than $\mathrm{T}_{\mathrm{sc}}$, but both normalized within $2 \mathrm{~h}$ (Fig. 2a, b), i.e. when still exposed to cold. Energy expenditure as measured by $\mathrm{O}_{2}$ consumption was significantly increased in the cold treatment group (Time, $p<0.001$; Treatment, $p<0.001$; Time $\times$ Treatment, $p<0.001$ ) (Fig. 2c), as was locomotor activity (Time, $p=0.014$; Treatment, $p=0.018$; Time $\times$ Treatment, $p=0.005$ ) (Fig. 2e). The respiratory exchange rate in the cold-exposed group slowly decreased during the first hour of cold exposure and stabilized at this lower value during the second hour of cold exposure (Time, $p=0.020$; Treatment, $p=0.090$; Time $\times$ Treatment, $p=0.008$ ) (Fig. $2 \mathrm{~d}$ ). Blood glucose concentrations remained stable throughout the 2-h exposure to a cold environment (Time, $p=$ 0.198 ; Treatment, $p=0.185$; Time $\times$ Treatment, $p=0.370$ ) (Fig. 2f).

\section{Retrodialysis of TRH in the PVN Increases TSH and} Corticosterone Concentrations, and Increases Plasma Thyroid Hormones after Two Hours

During the 2-h period of TRH MD in the PVN, plasma T3 and T4 concentrations did not change (Fig. 3a, c) 



Fig. 2. Effects of cold exposure on body temperature, metabolic parameters measured in calorimetric cages, and blood glucose concentrations. a Subcutaneous body temperature $\left(\mathrm{T}_{\mathrm{sc}}\right)$. b Intraperitoneal body temperature $\left(\mathrm{T}_{\mathrm{ip}}\right)$. c $\mathrm{O}_{2}$ consumption. d Respiratory exchange rate (RER). e Locomotor activity. $\mathbf{f}$ Glucose concentrations. $n=5-7$ per group. Asterisks indicate significant differences between groups at individual time points. Post hoc between cold and control groups, ${ }^{*} p<0.05,{ }^{* *} p<0.01,{ }^{* * *} p<0.001$. 
Fig. 3. Plasma thyroid hormones and corticosterone concentrations during and after TRH administration in the PVN. Plasma T3 (a), T4 (c), TSH (e), and corticosterone (g) concentrations at different time points during TRH administration. Data are shown as the absolute increase (delta) compared to the basal samples before treatments. $n=2-6$ per group. Basal values are shown in online supplementary Table S2. Plasma T3 (b), T4 (d), and TSH (f) concentrations at sacrifice after $2 \mathrm{~h}$ of TRH administration in the PVN. $n=8-10$ per group. Asterisks in a, c, and e indicate significant difference between groups at individual time points. Asterisks in $\mathbf{b}, \mathbf{d}$, and $\mathbf{f}$ indicate $t$ test significance between treatments. Post hoc between TRH and control groups, ${ }^{*} p<0.05,{ }^{* *} p<0.01,{ }^{* * *} p<0.001$.


g
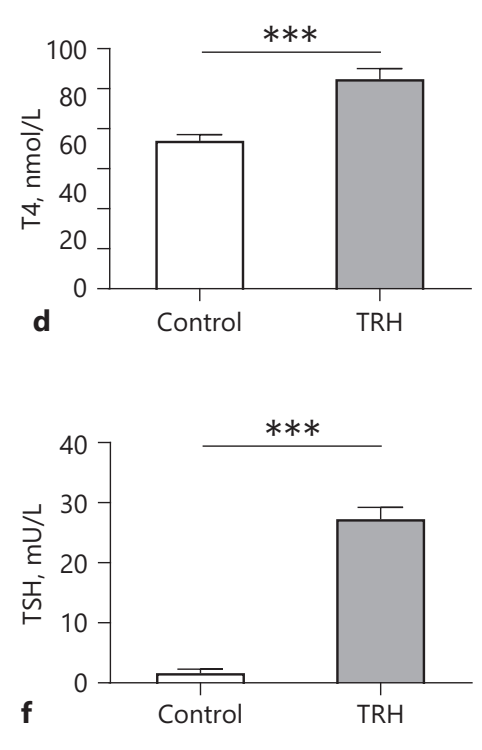

b
(Time, $p=0.610$; Treatment, $p=0.62$; Time $\times$ Treatment, $p=0.54$ and Time, $p=0.291$; Treatment, $p=0.08$; Time $\times$ Treatment, $p=0.16$ ), although at the final time point $(\mathrm{t}=120 \mathrm{~min})$ plasma T4 was significantly higher in the TRH group as compared to the control group $(p=0.022)$. TSH concentrations in plasma were significantly increased from $\mathrm{t}=20 \mathrm{~min}$ onwards (Time, $p<0.001$; Treatment, $p=0.013$; Time $\times$ Treatment, $p<0.001$ ) (Fig. 3e). In experiment $2 \mathrm{C}$, plasma $\mathrm{T} 3, \mathrm{~T} 4$, and TSH concentrations at sacrifice, i.e. $2 \mathrm{~h}$ after the start of the TRH admin- istration, were significantly increased (Fig. 3b, d, f). Plasma corticosterone concentrations also increased after TRH administration, reaching peak levels after $80 \mathrm{~min}$ (Time, $p<0.001$; Treatment, $p<0.001$; Time $\times$ Treatment, $p<0.0001$ ) (Fig. 3g).

\section{Retrodialysis of TRH in the PVN Increases Body \\ Temperature and Locomotor Activity}

Heat production is one of the most critical adaptions in coping with cold. To test whether TRH could mimic 


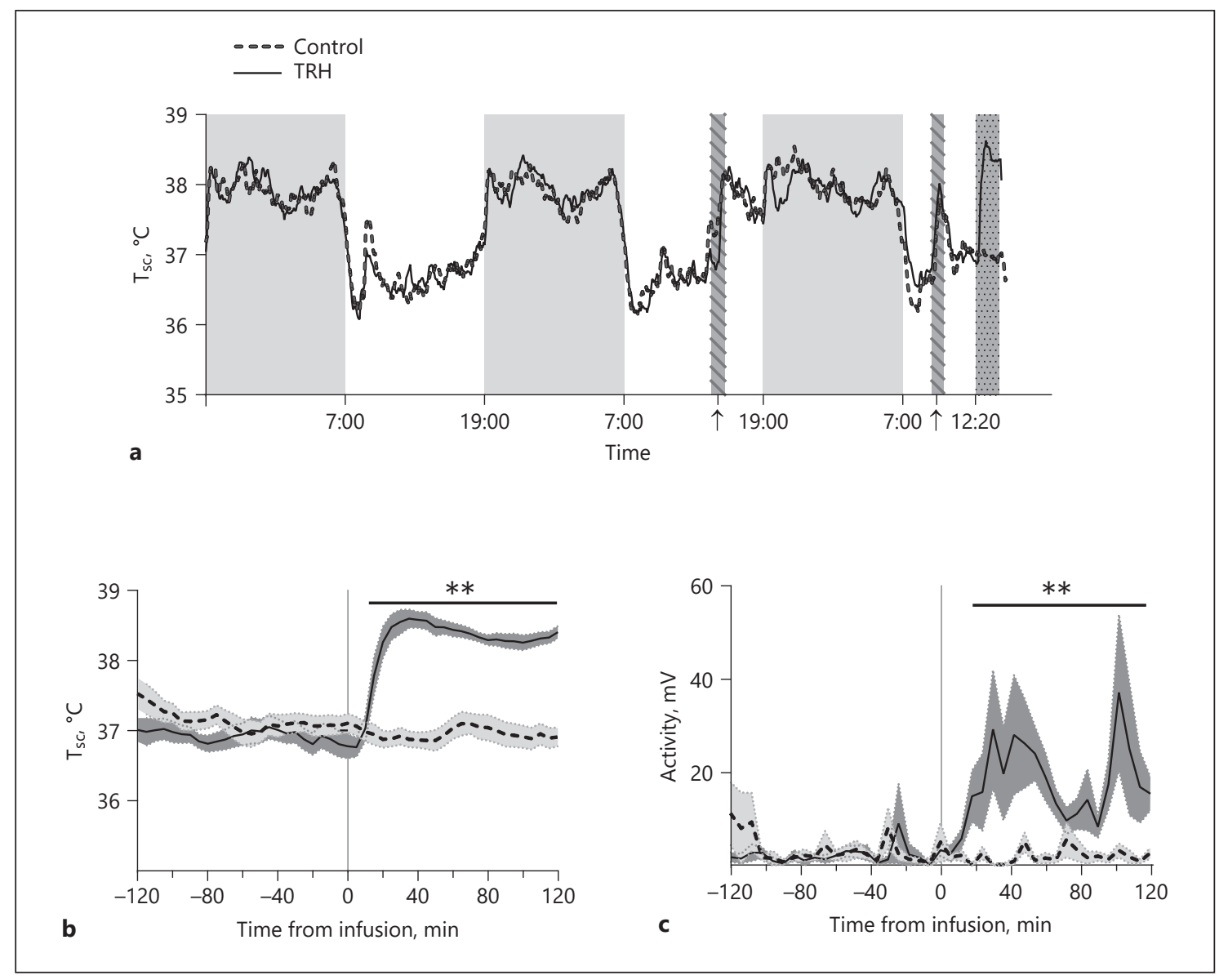

Fig. 4. Effects of TRH administration in the PVN on subcutaneous body temperature and locomotor activity. a Daily rhythms in body temperature before and during the experiment. Grey areas without pattern indicate the active phase (i.e., 12-h dark period). The two striped bars marked by arrows indicate the times that the animals were connected to, respectively, the chain and tubing. The dark grey stippled bar indicates the 2 -h period with TRH or vehicle ad-

the effects of cold on body physiology, we measured body temperature and locomotor activity before and after TRH administration. As expected, $\mathrm{T}_{\mathrm{sc}}$ showed a stable day/ night rhythm in both the TRH group and the control group with an amplitude of about $1.5^{\circ} \mathrm{C}$ and higher levels being present in the active phase (night) than in the inactive phase (day) (Fig. 4a). On the day of the experiment, we observed a fast increase in $\mathrm{T}_{\mathrm{sc}}$ already $15 \mathrm{~min}$ after starting the TRH administration (Time, $p<0.001$; Treatment, $p<0.001$; Time $\times$ Treatment, $p<0.001$ ). Moreover, the average of $\mathrm{T}_{\mathrm{sc}}$ was up to $1.6^{\circ} \mathrm{C}$ higher after TRH administration compared to the pre-treatment period (Fig. 4b). Along with increased body temperature, locomotor activity was also significantly increased in the TRH ministration. $\mathbf{b}$ Zoomed-in figure from a showing body temperature changes $2 \mathrm{~h}$ before and during the 2-h TRH or vehicle administration. c Locomotor activity $2 \mathrm{~h}$ before and during the 2 -h infusion experiment. Shadows along the line denote the standard error. $n=8-10$ per group. Two-way ANOVA was performed from $t=0$ to $t=120 \mathrm{~min}$. Asterisks indicate the overall significance of the Treatment effect. ${ }^{* *} p<0.01$.

group compared to the pre-treatment period $(p<0.001)$ (Fig. 4c). Body temperature and locomotor activity were not affected in the vehicle-perfused control group (Fig. $4 b, c)$.

\section{Retrodialysis of TRH in the PVN Increases Blood Glucose Concentrations and EGP through the Autonomic Nervous System}

Blood glucose concentrations increased more than $1 \mathrm{mmol} / \mathrm{L}$ within $40 \mathrm{~min}$ after the start of the TRH infusion compared to the control group (Time, $p<0.001$; Treatment, $p<0.001$; Time $\times$ Treatment, $p<0.001$ ) (Fig. 5a). EGP in the TRH group showed a gradual increase after the start of the TRH perfusion, which only 


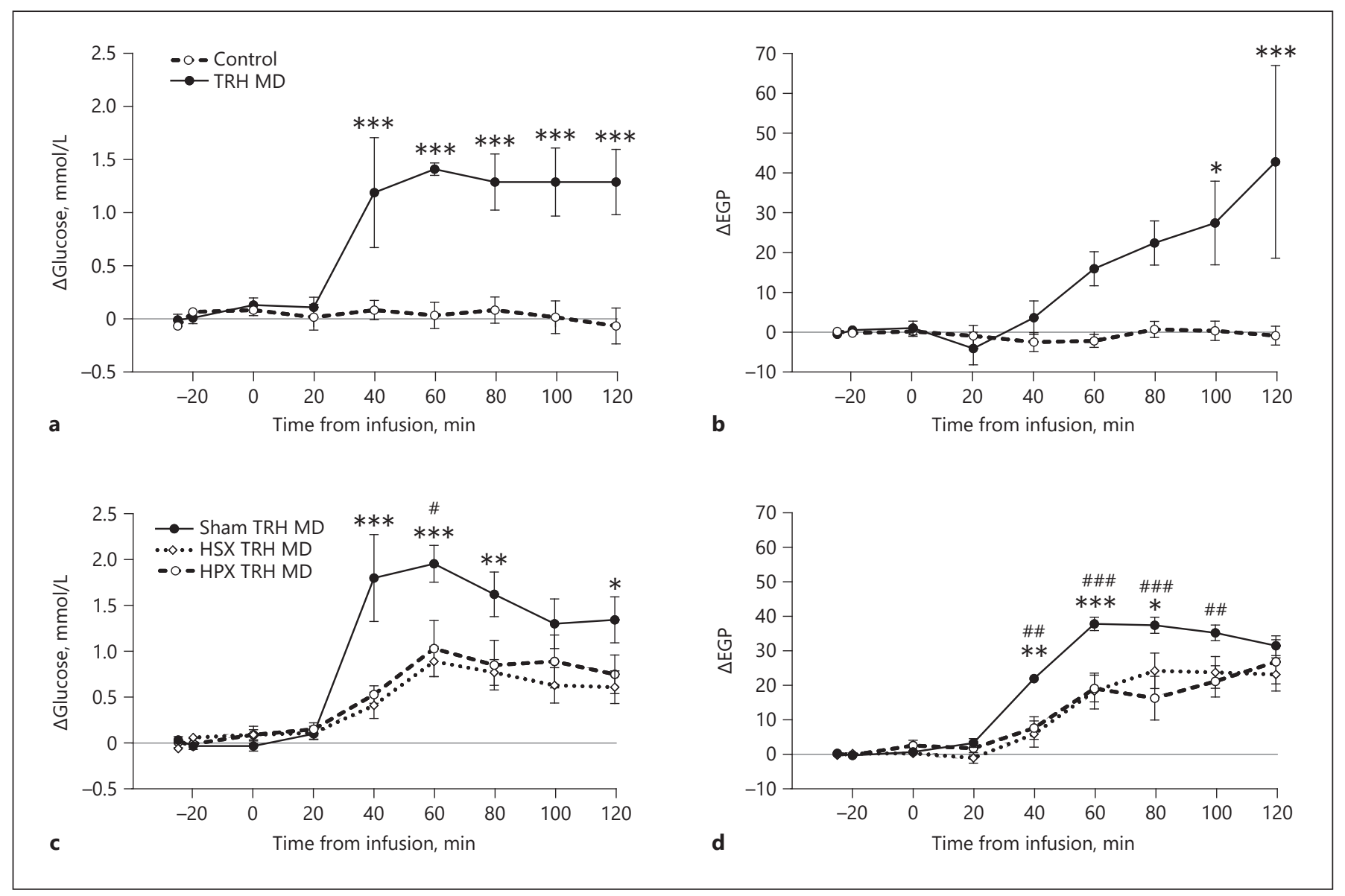

Fig. 5. Effects of TRH administration in the PVN and hepatic sympathectomy (HSX) or parasympathectomy (HPX) on blood glucose concentrations and EGP. a, c Blood glucose concentrations. b, d Endogenous glucose production (EGP). Data are shown as the absolute increase (delta) compared to the basal samples before treatments. Basal values are shown in online supplementary Table
S2. $n=5-10$ per group. For post hoc analysis, asterisk indicates significant difference between the sham TRH MD and HSX TRH MD groups at individual time points. Number sign indicates significant difference between sham TRH MD and HPX TRH MD groups at individual time points. ${ }^{*}{ }^{\#} p<0.05,{ }^{* *} p<0.01$, ***,\#\#\# $p<0.001$. reached significance $100 \mathrm{~min}$ after the start of the perfusion (Time, $p<0.001$; Treatment, $p=0.007$; Time $\times$ Treatment, $p<0.001$ ) (Fig. 5b). To investigate whether the TRH effects on glucose metabolism were mediated via the autonomic nervous system, we repeated the previous experiment in hepatic sympathetic or parasympathetic denervated rats. TRH administration significantly increased blood glucose concentrations in sham-operated animals compared to baseline $(p<0.0001)$. HSX greatly reduced this effect (55.2\% decrease compared to sham), but did not completely abolish the TRH-induced increase in glucose (Time, $p<0.001$; Treatment, $p=0.003$; Time $\times$ Treatment, $p<0.001$ ) (Fig. 5c). HPX also attenuated the TRHinduced hyperglycemia $(47.6 \%$ decrease compared to sham) (Time, $p<0.001$; Treatment, $p=0.037$; Time $\times$ Treatment, $p=0.011$ ) (Fig. $5 c$ ). In addition, both HSX and HPX significantly decreased the TRH-induced increase in EGP (36.5 and $45.1 \%$ decrease compared to sham, respectively) (Time, $p<0.001$; Treatment, $p=$ 0.012 ; Time $\times$ Treatment, $p<0.001$, for HSX vs. sham; and Time, $p<0.001$; Treatment, $p=0.005$; Time $\times$ Treatment, $p<0.001$, for HPX vs. sham) (Fig. $5 \mathrm{~d}$ ).

\section{Both Cold Exposure and Retrodialysis of TRH in the}

PVN Increase Gluconeogenesis and Lipolysis Gene

Expression in the Liver and BAT, Respectively

In order to understand the mechanism behind the thermogenesis and changes in glucose metabolism dur- 




Fig. 6. Gene expression changes in the liver $(\mathbf{a}, \mathbf{c})$ and BAT $(\mathbf{b}, \mathbf{d})$ after cold exposure $(\mathbf{a}, \mathbf{b})$ and TRH administration in the PVN $(\mathbf{c}, \mathbf{d})$. Gene expressions are relative to the geometric mean of two reference genes (Gapdh and $H$ prt) and normalized to the corresponding controls. $n=6-10$ per group. ${ }^{*} p<0.05,{ }^{* *} p<0.01,{ }^{* * *} p<0.001$.

ing cold exposure and TRH administration, we analyzed the expression profile of a number of genes that are involved in glucose metabolism and heat production, in the liver and BAT, respectively. In the liver (Fig. 6a, c), Pgcla mRNA expression was not changed by cold exposure, but tended to increase $(p=0.067)$ after TRH administration. Expression of Pgclb was significantly increased in both the cold and TRH treatment groups. Pparg gene expression was decreased in response to TRH treatment, but not cold exposure. Gene expression of Pepck, a key enzyme in controlling gluconeogenesis, was greatly increased in both the cold and TRH groups. Glucose-6-phosphatase (G6pase), the enzyme that hydrolyzes glucose-6-phos- phate into free glucose, showed a trend towards increased expression after both cold exposure $(p=0.060)$ and TRH administration $(p=0.086)$. Farnasoid $\mathrm{X}$ receptor $(F x r)$ expression was markedly decreased by TRH, but not cold treatment. Expression of the T3-responsive gene type 1 deiodinase (Dio1) did not change after either cold exposure or TRH administration.

In BAT (see Fig. 6b, d), gene expression of the transcriptional factor Pgcla was upregulated both by cold and TRH treatment compared to their controls. Expression of Pparg was increased by TRH administration, but unchanged during cold exposure. As to glucose metabolism, glucose transporter 4 (Glut4) showed a trend towards an 
increase $(p=0.06)$, and glucokinase (Gck) mRNA was significantly increased after TRH treatment, but both were unchanged after cold exposure. For lipid metabolism in BAT, lipoprotein lipase $1(L p l)$ and hormone-sensitive lipase $(H s l)$, two enzymes involved in triglyceride uptake and hydrolysis, were significantly increased in the TRH group. Cold exposure induced a significant increase in $L p l$ but not $H s l$ expression. Type 2 deiodinase (Dio2), an essential enzyme converting T4 into T3, was markedly increased (5-fold) by both cold and TRH treatment. Gene expression of the uncoupling protein $(U c p 1)$ did not change by either cold or TRH treatment. Expression of the beta-adrenergic receptor $A d r b 3$ did not differ significantly in either the cold- or TRH-treated animals compared to their controls. Heat shock protein (Hsp90) was significantly increased by both cold and TRH treatment.

\section{Discussion}

Both cold exposure and TRH administration locally in the PVN rapidly, i.e. within $30 \mathrm{~min}$, increased body temperature, locomotor activity, glucose metabolism, plasma TSH, and corticosterone concentrations. Molecular changes in the liver and BAT were in line with these physiological data by showing increased expression of genes involved in gluconeogenesis and thermogenesis, respectively, again after both cold exposure and TRH administration. The TRHinduced increase in glucose production was partly mediated by the autonomic nervous system. The potent activation of TRH neurons in the hypothalamus during cold exposure is well known $[1,21,34]$. Our current results show that the PVN may be one of the target areas needed in effectuating the changes induced by the increased hypothalamic expression of TRH. We conclude that the increased release of TRH in the PVN activates a neural mechanism that induces metabolic and behavioral changes in line with a key role in the cold-defensive response.

Plasma glucose homeostasis is maintained by balancing glucose uptake and glucose production, with the liver as the major glucose-producing organ $[35,36]$. Despite increased liver gluconeogenesis, as suggested by the enhanced gene expression of Pepck, G6pase, and Pgc1b, blood glucose concentrations did not change during the 2-h cold exposure. Likely, the increased glucose produced was utilized by heat-producing organs such as BAT and muscle, as several studies have shown that cold exposure induces increased glucose uptake and carbohydrate oxidation in muscle and BAT [37-39]. Interestingly, TRH administration locally in the PVN also upregulated gene expression in the gluconeogenic pathway in liver, e.g. Pepck, G6pase, and Pgc1 family (Fig. 6c) and indeed at the same time increased EGP. In contrast to cold exposure, central TRH administration resulted in a pronounced increase in plasma glucose concentrations, probably because these animals were not exposed to cold. The increased glucose production is consistent with the previously reported central hyperglycemic effect of TRH [40, 41], but difficult to reconcile with hyperglycemia reported in TRH deficient mice [9]. Furthermore, a stronger effect was observed when TRH was administered specifically in the PVN, as compared to an intracerebroventricular (ICV) infusion (online suppl. Fig. S1), indicating that the ICV effects were probably effectuated via the PVN. Indeed, the autonomic control of liver glucose metabolism by the PVN has been well recognized [42, 43]. Consistently, both HSX and HPX significantly blocked the TRH-induced increase in plasma glucose. This HSX/ HPX induced reduction of the TRH-induced hyperglycemia is probably due to a blockage of glucose production in liver, as both HSX and HPX also attenuated the TRHinduced increase in EGP. The neural mechanism of this effect is further stressed by the fact that HSX/HPX reduced the TRH-induced EGP increases despite an intact corticosterone response (online suppl. Fig. S2), i.e. a wellknown stimulator [19] of hepatic glucose production [44]. Notably, HSX and HPX each only blocked approximately half of the TRH-induced EGP and plasma glucose increase, indicating that most likely a total denervation is needed for a complete blocking effect or that a hormonal component such as the HPA axis is involved as well.

Animals in a cold environment reduce their heat loss and enhance their metabolic rate in order to maintain thermal homeostasis $[45,46]$. In line with this, we observed an accelerated metabolic rate as reflected by the increased $\mathrm{O}_{2}$ consumption during cold exposure and a resultant transient increase in body temperature. Cold exposure also led to increased locomotor activity, which may contribute to an increase in body temperature. These effects might be mediated by TRH as suggested by our current results and those of previous studies [4, 47, 48]. Indeed, TRH administration in the PVN increased body temperature in a rather prompt and sustained way. Although our estimated dose of TRH administration $(0.2 \mu \mathrm{g} / \mathrm{h})$ was rather low compared to other studies $(0.1-40 \mu \mathrm{g}$ single injection) $[4,16$, 26-28], long-term exposure to TRH could result in downregulation of TRH receptors, which may account for the slight drop in temperature after $40 \mathrm{~min}$ of TRH infusion (Fig. 4b). Furthermore, at the molecular level, TRH administration in the PVN stimulated the expression of genes 
facilitating energy utilization and metabolic activity in BAT, very much similar to the changes induced by cold exposure. Elevated expression of $\mathrm{Lpl}$ and Glut4 mRNA in BAT suggests increased fatty acid and glucose uptake and the increased expression of $H s l$, an important enzyme for triglyceride hydrolysis, will result in an increased availability of free fatty acids for energy production. Taken together, the transcriptional changes show that both cold exposure and TRH administration in the PVN stimulate fuel recruitment and mobilization (e.g., lipids and glucose) in BAT, an essential preparation for BAT thermogenesis [37, 49]. Other changes in BAT in response to cold are mitochondrial biogenesis and adipocyte proliferation, which at the molecular level are revealed by an increased expression of transcription factors such as Pgcla and Pparg [50, 51]. In line, TRH administration in the PVN indeed also significantly increased Pgcla and Pparg mRNA, suggesting a boost of BAT activation. Additionally, the remarkable increase in Dio 2 mRNA by both cold and TRH treatment, indicating an increase in local T3 production, provides another important step towards increased BAT thermogenesis $[52,53]$. Surprisingly, expression of $U c p 1$, the key protein in BAT that uncouples substrate oxidation from ATP synthesis to heat production, did not change under either cold or TRH treatment. Of note, an increased BAT adrenergic responsiveness could serve as a pre-UCP1 step enhancing BAT thermogenesis [54]. Moreover, UCP1 activity may have been increased without changing its expression [55]. It is possible that cold exposure or TRH administration increased adrenergic responsiveness, so that BAT heat production was elevated without changing UCP1 expression. An earlier study by Lin [56] showed that hyperthermia after an intrahypothalamic TRH injection in rats was due to both increased heat production and cutaneous vasoconstriction. It is likely that a decreased heat loss also contributed to the increased temperature observed in our results.

TRH administration in the PVN increased plasma TSH concentrations shortly after the start of the perfusion. TSH has been suggested to have a thermogenic effect and can increase Ucp 1 expression in rat brown adipocytes $[57,58]$. At present, we cannot exclude that in addition to the neural effects of TRH, plasma TSH may have a direct effect on glucose metabolism and thermoregulation, although Ucp1 expression in BAT was not upregulated. One may argue that the increased concentrations of plasma thyroid hormones caused the effects observed during TRH administration. However, we believe that the effects of thyroid hormone in the TRH MD experiment, if any, were subtle. First, the changes in TH

TRH in the PVN and the Cold Defense Response levels occurred only at the end of the 2-h TRH perfusion, i.e. long after the onset of the effects on glucose, corticosterone, locomotion, and body temperature. Secondly, TRH-induced hyperthermia cannot be mimicked by thyroid hormone administration alone as shown by previous studies [48]. Thirdly, expression of Dio1, a T3-sensitive gene in the liver, was not changed. Of note, our recent work also suggests a neural and endocrine effect of systemic TRH on BAT activation in human [6].

The PVN neurons send dense projections to the brainstem and spinal cord to control autonomic responses [59, 60], as well as to other brain areas important for glucose metabolism and thermoregulation [61-63]. Previously, a number of studies have demonstrated the implication of several hypothalamic areas, such as the preoptic area and dorsomedial nucleus, in the thermoregulatory effects of TRH $[4,5,64]$; however, little or no attention has been paid to TRH effects in the PVN during cold exposure on glucose mobilization and BAT thermogenesis. The PVN contains a moderately dense number of TRH receptors $[17,18]$ as well as direct TRH-immunoreactive synaptic inputs to TRH neurons $[19,20]$. These observations indicate that TRH may modulate TRH and/or other neurons in the PVN, e.g. CRH neurons. The increased TSH release after TRH administration in the PVN also supports the existence of short-cut autocrine or paracrine circuits for positive feedback activating TRH neurons as also proposed earlier $[19,20]$. On the other hand, the PVN may have both stimulatory $[15,65,66]$ and inhibitory effects on thermoregulation $[14,67,68]$, depending on different neurotransmitters involved, suggesting a heterogeneity in the PVN neurons that are involved in thermoregulation. Interestingly, a recent study by Song et al. [69] showed that a group of preoptic Vglut2+ neurons inhibited thermogenesis by exciting corticotropin-releasing hormone (CRH) but not TRH neurons in the PVN. Taken together, our current results suggest a differential control of thermoregulation by distinct neuronal populations in the PVN, i.e. CRH neurons inhibiting and TRH neurons stimulating thermogenesis. However, whether the TRH released in the PVN is derived from TRH neurons within the PVN or extra PVN areas cannot be deduced from the current experiments. Future experiments should indicate which neurons within the PVN, i.e. TRH or nonTRH containing, are mediating these effects.

In conclusion, our study demonstrates that TRH administration in the PVN induces metabolic and behavioral changes mimicking those during cold exposure, which places the PVN in the center of the cold defense mechanism. 


\section{Acknowledgements}

We would like to thank the staff of the Laboratory of Endocrinology for measuring serum thyroid hormones and the staff of the Stable Isotope Lab for EGP measurement. This project was funded by a grant from the China Exchange Program (CEP) of the Royal Netherlands Academy of Sciences and the Chinese Academy of Sciences (grant \#11CDP001, to E.Fl.) and by a grant from the Chinese Scholarship Council (CSC) (CSC ID: 201206340004, to Z.Z.).

\section{Author Contributions}

Z.Z. designed and performed the experiments, analyzed data, and wrote the paper; F.M., L.Z. E.Fo., M.T.A. performed the experiments and analyzed the data; C.A.H. and J.Z. interpreted the data and revised the paper; P.H.B., A.B., E.Fl., and A.K. designed the experiments, interpreted the data and revised the paper. All authors reviewed and approved the final version of the manuscript.

\section{Disclosure Statement}

The authors do not have any competing interests.

\section{References}

1 Perello M, Stuart RC, Vaslet CA, Nillni EA: Cold exposure increases the biosynthesis and proteolytic processing of prothyrotropin-releasing hormone in the hypothalamic paraventricular nucleus via beta-adrenoreceptors. Endocrinology 2007;148:4952-4964.

2 Nillni EA, Sevarino KA: The biology of prothyrotropin-releasing hormone-derived peptides. Endocr Rev 1999;20:599-648.

3 Marubashi S, Kunii Y, Tominaga M, Sasaki H: Modulation of plasma glucose levels by thyrotropin-releasing hormone administered intracerebroventricularly in the rat. Neuroendocrinology 1988;48:640-644.

4 Boschi G, Rips R: Effects of thyrotropin releasing hormone injections into different loci of rat brain on core temperature. Neurosci Lett 1981;23:93-98.

5 Shintani M, Tamura Y, Monden M, Shiomi $\mathrm{H}$ : Thyrotropin-releasing hormone induced thermogenesis in Syrian hamsters: site of action and receptor subtype. Brain Res 2005 1039:22-29.

6 Heinen CA, Zhang Z, Klieverik LP, de Wit TC, Poel E, Yaqub M, Boelen A, Kalsbeek A, Bisschop PH, van Trotsenburg ASP, Verberne HJ, Booij J, Fliers E: Effects of intravenous thyrotropin-releasing hormone on (18)F-fluorodeoxyglucose uptake in human brown adipose tissue: a randomized controlled trial. Eur J Endocrinol 2018;179:31-38

7 Yamada M, Satoh T, Mori M: Mice lacking the thyrotropin-releasing hormone gene: what do they tell us? Thyroid 2003;13:1111-1121.

8 Nillni EA, Xie W, Mulcahy L, Sanchez VC, Wetsel WC: Deficiencies in pro-thyrotropinreleasing hormone processing and abnormalities in thermoregulation in Cpefat/fat mice. J Biol Chem 2002;277:48587-48595.

9 Yamada M, Saga Y, Shibusawa N, Hirato J, Murakami M, Iwasaki T, Hashimoto K, Satoh T, Wakabayashi K, Taketo MM, Mori M: Tertiary hypothyroidism and hyperglycemia in mice with targeted disruption of the thyrotropin-releasing hormone gene. Proc Natl Acad Sci USA 1997;94:10862-10867.
10 Stern JE: Neuroendocrine-autonomic integration in the paraventricular nucleus: novel roles for dendritically released neuropeptides. J Neuroendocrinol 2015;27:487-497.

11 Kenney MJ, Weiss ML, Haywood JR: The paraventricular nucleus: an important component of the central neurocircuitry regulating sympathetic nerve outflow. Acta Physiol Scand 2003;177:7-15.

12 Lee SK, Ryu PD, Lee SY: Differential distributions of neuropeptides in hypothalamic paraventricular nucleus neurons projecting to the rostral ventrolateral medulla in the rat. Neurosci Lett 2013;556:160-165.

13 Liu J, Bisschop PH, Eggels L, Foppen E, Ackermans MT, Zhou JN, Fliers E, Kalsbeek A: Intrahypothalamic estradiol regulates glucose metabolism via the sympathetic nervous system in female rats. Diabetes 2013;62:435-443.

14 Shi YC, Lau J, Lin Z, Zhang H, Zhai L, Sperk G, Heilbronn R, Mietzsch M, Weger S, Huang XF, Enriquez RF, Baldock PA, Zhang L, Sainsbury A, Herzog H, Lin S: Arcuate NPY controls sympathetic output and BAT function via a relay of tyrosine hydroxylase neurons in the PVN. Cell Metab 2013;17:236-248.

15 Masaki T, Yasuda T, Yoshimatsu H: Apelin-13 microinjection into the paraventricular nucleus increased sympathetic nerve activity innervating brown adipose tissue in rats. Brain Res Bull 2012;87:540-543.

16 Shen DC, Lin MT, Shian LR: Thyrotropin-releasing hormone-induced hyperglycemia: possible involvement of cholinergic receptors in the lateral hypothalamus. Neuroendocrinology 1985;41:499-503.

17 Sun Y, Lu X, Gershengorn MC: Thyrotropinreleasing hormone receptors - similarities and differences. J Mol Endocrinol 2003;30: 87-97.

18 Rostène WH, Morgat JL, Dussaillant M, Rainbow TC, Sarrieau A, Vial M, Rosselin G: In vitro biochemical characterization and autoradiographic distribution of ${ }^{3} \mathrm{H}$-thyrotropinreleasing hormone binding sites in rat brain sections. Neuroendocrinology 1984;39:81-86.
19 Kiss J, Halasz B: Ultrastructural analysis of the innervation of TRH-immunoreactive neuronal elements located in the periventricular subdivision of the paraventricular nucleus of the rat hypothalamus. Brain Res 1990;532: 107-114.

20 Toni R, Jackson IM, Lechan RM: Thyrotropin-releasing-hormone-immunoreactive innervation of thyrotropin-releasing-hormonetuberoinfundibular neurons in rat hypothalamus: anatomical basis to suggest ultrashort feedback regulation. Neuroendocrinology 1990;52:422-428.

21 Cabral A, Valdivia S, Reynaldo M, Cyr NE, Nillni EA, Perello M: Short-term cold exposure activates TRH neurons exclusively in the hypothalamic paraventricular nucleus and raphe pallidus. Neurosci Lett 2012;518:86-91.

22 Fiedler J, Jara P, Luza S, Dorfman M, Grouselle D, Rage F, Lara HE, Arancibia S: Cold stress induces metabolic activation of thyrotrophin-releasing hormone-synthesising neurones in the magnocellular division of the hypothalamic paraventricular nucleus and concomitantly changes ovarian sympathetic activity parameters. J Neuroendocrinol 2006; 18: 367-376.

23 Paxinos G, Watson C: The Rat Brain in Stereotaxic Coordinates, ed 6. Amsterdam, Elsevier, 2006.

24 Klieverik LP, Janssen SF, van Riel A, Foppen E, Bisschop PH, Serlie MJ, Boelen A, Ackermans MT, Sauerwein HP, Fliers E, Kalsbeek A: Thyroid hormone modulates glucose production via a sympathetic pathway from the hypothalamic paraventricular nucleus to the liver. Proc Natl Acad Sci USA 2009; 106:59665971.

25 Kalsbeek A, La Fleur S, Van Heijningen C, Buijs RM: Suprachiasmatic GABAergic inputs to the paraventricular nucleus control plasma glucose concentrations in the rat via sympathetic innervation of the liver. J Neurosci 2004;24:7604-7613. 
26 Lin MT, Chandra A, Chern YF, Tsay BL: Effects of thyrotrophic-releasing hormone (TRH) on thermoregulation in the rat. Experientia 1980;36:1077-1078.

27 Amir S, Pollock R, Lagiorgia M: Intra-hypothalamic injection of thyrotropin-releasing hormone suppresses brown fat thermogenesis in the anaesthetized rat. Brain Res 1989; 478:361-364.

28 Hori T, Yamasaki M, Asami T, Koga H, Kiyohara T: Responses of anterior hypothalamicpreoptic thermosensitive neurons to thyrotropin releasing hormone and cyclo(HisPro). Neuropharmacology 1988;27:895-901.

29 la Fleur SE, Kalsbeek A, Wortel J, Fekkes ML, Buijs RM: A daily rhythm in glucose tolerance: a role for the suprachiasmatic nucleus. Diabetes 2001;50:1237-1243.

30 Ackermans MT, Pereira Arias AM, Bisschop PH, Endert E, Sauerwein HP, Romijn JA: The quantification of gluconeogenesis in healthy men by $(2) \mathrm{H} 2 \mathrm{O}$ and [2-(13)C]glycerol yields different results: rates of gluconeogenesis in healthy men measured with (2) $\mathrm{H} 2 \mathrm{O}$ are higher than those measured with [2-(13)C]glycerol. J Clin Endocrinol Metab 2001;86:22202226.

31 Steele R: Influences of glucose loading and of injected insulin on hepatic glucose output. Ann NY Acad Sci 1959;82:420-430.

32 Klieverik LP, Sauerwein HP, Ackermans MT, Boelen A, Kalsbeek A, Fliers E: Effects of thyrotoxicosis and selective hepatic autonomic denervation on hepatic glucose metabolism in rats. Am J Physiol Endocrinol Metab 2008; 294:E513-E520.

33 Ruijter JM, Ramakers C, Hoogaars WM, Karlen Y, Bakker O, van den Hoff MJ, Moorman AF: Amplification efficiency: linking baseline and bias in the analysis of quantitative PCR data. Nucleic Acids Res 2009;37:e45.

34 Sanchez E, Uribe RM, Corkidi G, Zoeller RT, Cisneros M, Zacarias M, Morales-Chapa C, Charli JL, Joseph-Bravo P: Differential responses of thyrotropin-releasing hormone (TRH) neurons to cold exposure or suckling indicate functional heterogeneity of the TRH system in the paraventricular nucleus of the rat hypothalamus. Neuroendocrinology 2001;74:407-422.

35 Rui L: Energy metabolism in the liver. Compr Physiol 2014;4:177-197.

36 Yeo R, Sawdon M: Hormonal control of metabolism: regulation of plasma glucose. Anaesth Intensive Care Med 2013;14:296-300.

37 Yu XX, Lewin DA, Forrest W, Adams SH: Cold elicits the simultaneous induction of fatty acid synthesis and beta-oxidation in murine brown adipose tissue: prediction from differential gene expression and confirmation in vivo. FASEB J 2002;16:155-168.

38 Vallerand AL, Jacobs I: Energy metabolism during cold exposure. Int J Sports Med 1992; 13(suppl 1):S191-S193.

39 Labbe SM, Caron A, Bakan I, Laplante M, Carpentier AC, Lecomte R, Richard D: In vivo measurement of energy substrate contribu- tion to cold-induced brown adipose tissue thermogenesis. FASEB J 2015;29:2046-2058.

40 Brown MR: Thyrotropin releasing factor: a putative CNS regulator of the autonomic nervous system. Life Sci 1981;28:1789-1795.

41 Kabayama Y, Kato Y, Tojo K, Shimatsu A, Ohta H, Imura H: Central effects of DN1417, a novel TRH analog, on plasma glucose and catecholamines in conscious rats. Life Sci 1985;36:1287-1294.

42 Kalsbeek A, Bruinstroop E, Yi CX, Klieverik LP, La Fleur SE, Fliers E: Hypothalamic control of energy metabolism via the autonomic nervous system. Ann NY Acad Sci 2010;1212: 114-129.

43 O'Hare JD, Zsombok A: Brain-liver connections: role of the pre-autonomic PVN neurons. Am J Physiol Endocrinol Metab 2016; 310:E183-E189.

44 Kuo T, McQueen A, Chen TC, Wang JC: Regulation of glucose homeostasis by glucocorticoids. Adv Exp Med Biol 2015;872:99-126.

45 Terrien J, Perret M, Aujard F: Behavioral thermoregulation in mammals: a review. Front Biosci 2011;16:1428-1444.

46 Cannon B, Nedergaard J: Nonshivering thermogenesis and its adequate measurement in metabolic studies. J Exp Biol 2011;214:242253.

47 Vogel RA, Cooper BR, Barlow TS, Prange AJ Jr, Mueller RA, Breese GR: Effects of thyrotropin-releasing hormone on locomotor activity, operant performance and ingestive behavior. J Pharmacol Exp Ther 1979;208:161-168.

48 Clark WG, Lipton JM: Brain and pituitary peptides in thermoregulation. Pharmacol Ther 1983;22:249-297.

49 Cannon B, Nedergaard J: Brown adipose tissue: function and physiological significance. Physiol Rev 2004;84:277-359.

50 Puigserver P, Wu Z, Park CW, Graves R, Wright M, Spiegelman BM: A cold-inducible coactivator of nuclear receptors linked to adaptive thermogenesis. Cell 1998;92:829839.

51 Villena JA: New insights into PGC-1 coactivators: redefining their role in the regulation of mitochondrial function and beyond. FEBS J 2015;282:647-672.

52 Silva JE: Thyroid hormone control of thermogenesis and energy balance. Thyroid 1995;5: 481-492.

53 Obregon MJ: Adipose tissues and thyroid hormones. Front Physiol 2014;5:479.

54 Ribeiro MO, Lebrun FL, Christoffolete MA, Branco M, Crescenzi A, Carvalho SD, Negrao N, Bianco AC: Evidence of UCP1-independent regulation of norepinephrine-induced thermogenesis in brown fat. Am J Physiol Endocrinol Metab 2000;279:E314-E322.

55 Carroll AM, Porter RK, Morrice NA: Identification of serine phosphorylation in mitochondrial uncoupling protein 1. Biochim Biophys Acta 2008;1777:1060-1065.

56 Lin MT: Metabolic, respiratory, vasomotor, and body temperature responses to TRH, angiotensin II, substance P, neurotensin, soma- tostatin, LH-RH, beta-endorphin, oxytocin, or vasopressin in the rat. Adv Biosci 1982;38: 229-251.

57 Murakami M, Kamiya Y, Morimura T, Araki O, Imamura M, Ogiwara T, Mizuma H, Mori M: Thyrotropin receptors in brown adipose tissue: thyrotropin stimulates type II iodothyronine deiodinase and uncoupling protein-1 in brown adipocytes. Endocrinology 2001; 142:1195-1201.

58 Martinez-deMena R, Anedda A, Cadenas S, Obregon MJ: TSH effects on thermogenesis in rat brown adipocytes. Mol Cell Endocrinol 2015;404:151-158.

59 Arancibia S, Rage F, Astier H, Tapia-Arancibia L: Neuroendocrine and autonomous mechanisms underlying thermoregulation in cold environment. Neuroendocrinology 1996;64:257-267.

60 Jansen ASP, Wessendorf MW, Loewy AD: Transneuronal labeling of CNS neuropeptide and monoamine neurons after pseudorabies virus injections into the stellate ganglion. Brain Res 1995;683:1-24.

61 Bisschop PH, Fliers E, Kalsbeek A: Autonomic regulation of hepatic glucose production. Compr Physiol 2015;5:147-165.

62 Ao Y, Toy N, Song MK, Go VL, Yang H: Altered glucose and insulin responses to brain medullary thyrotropin-releasing hormone (TRH)-induced autonomic activation in type 2 diabetic Goto-Kakizaki rats. Endocrinology 2005; 146:5425-5432.

63 Wittmann G, Fuzesi T, Singru PS, Liposits Z, Lechan RM, Fekete C: Efferent projections of thyrotropin-releasing hormone-synthesizing neurons residing in the anterior parvocellular subdivision of the hypothalamic paraventricular nucleus. J Compar Neurol 2009;515:313330

64 Morrison SF, Madden CJ: Central nervous system regulation of brown adipose tissue. Compr Physiol 2014;4:1677-1713.

65 Amir S: Stimulation of the paraventricular nucleus with glutamate activates interscapular brown adipose tissue thermogenesis in rats. Brain Res 1990;508:152-155.

66 Yasuda T, Masaki T, Sakata T, Yoshimatsu H: Hypothalamic neuronal histamine regulates sympathetic nerve activity and expression of uncoupling protein $1 \mathrm{mRNA}$ in brown adipose tissue in rats. Neuroscience 2004; 125 : 535-540.

67 Egawa M, Yoshimatsu H, Bray GA: Neuropeptide $\mathrm{Y}$ suppresses sympathetic activity to interscapular brown adipose tissue in rats. Am J Physiol 1991;260:R328-R334.

68 Madden CJ, Morrison SF: Neurons in the paraventricular nucleus of the hypothalamus inhibit sympathetic outflow to brown adipose tissue. Am J Physiol Regul Integr Comp Physiol 2009;296:R831-R843.

69 Song K, Wang H, Kamm GB, Pohle J, Reis FC, Heppenstall P, Wende H, Siemens J: The TRPM2 channel is a hypothalamic heat sensor that limits fever and can drive hypothermia. Science 2016;353:1393-1398. 